\title{
LAS ESCULTURAS IBÉRICAS DEL CERRO DE LOS SANTOS EN LA EXPOSICIÓN UNIVERSAL DE VIENA (1873)
}

\author{
IBERIAN IRON AGE SCULPTURES FROM CERRO DE LOS SANTOS IN THE VIENNA INTERNATIONAL \\ EXHIBITION (1873)
}

TERESA CHAPA BRUNET

Universidad Complutense

JULIO GONZÁLEZ ALCALDE

Museo Nacional de Antropología

\section{INTRODUCCIÓN}

El temprano hallazgo del Cerro de los Santos y de sus espectaculares esculturas abrió la puerta a la definición de una cultura original, en una época en la que todavía no se habían fijado ni las características ni la cronología de estas manifestaciones que luego serían calificadas como «ibéricas». Este proceso formativo incluiría, en el caso del yacimiento albacetense, una larga sucesión de circunstancias nada comunes que condicionaron la formación de las colecciones, su estudio y su interpretación. Desde el momento de su descubrimiento oficial, el Museo Arqueológico Nacional (M.A.N.) se interesó por la incorporación de un buen número de esculturas y otros materiales, que constituyeron una de las colecciones más admiradas de sus salas. La novedad de los hallazgos, complicada sin duda por la presencia de un número notable de falsificaciones con fuerte carga epigráfica, dificultó notablemente su adscripción cultural en esta primera etapa, en la que existen opiniones dispares en los diversos foros.

La convocatoria de la Exposición Universal de Viena de 1873 supuso una gran oportunidad para que la colección del Cerro de los Santos se diera a conocer en Europa a través de una serie de vaciados de las piezas consideradas más relevantes. Esta muestra fue considerada por el gobierno de la Primera República como una excelente oportunidad para demostrar que España podía competir en este ámbito internacional, después de la difícil situación política y económica que había dado lugar a la Revolución de 1868. La participación española en general y en concreto la fabricación, envío y exposición de los moldes del Cerro, supuso un gran esfuerzo organizativo. La intención era revelar la existencia de un nuevo arte plenamente nacional, así como recabar opiniones en el mundo académico especializado sobre su interpretación, cronología y posibles paralelos. El objetivo de este trabajo es precisamente trazar la trayectoria de las esculturas del Cerro de los Santos desde su descubrimiento a su presencia en Viena, una etapa que, a pesar de la bibliografía que ha generado, presenta todavía muchos puntos de interés que cabe seguir investigando.

ANTES DE VIENA: EL DESCUBRIMIENTO DEL CERRO DE LOS SANTOS Y LA INCORPORACIÓN DE SUS MATERIALES AL MUSEO ARQUEOLÓGICO NACIONAL

Las circunstancias que rodearon a los diversos y progresivos hallazgos en el Cerro de los Santos son importantes para caracterizar las colecciones que fueron incorporándose al M.A.N., y permiten entender la selección de piezas que se enviaron a Viena, su valoración provisional y las expectativas que los especialistas depositaron en esta expedición.

La primera etapa en el reconocimiento de este lugar como yacimiento arqueológico se había iniciado algo más de 40 años antes, hacia 1830, cuando se taló el bosque que cubría el Cerro, siendo aprovechadas muchas de sus esculturas como simple material pétreo en las construcciones del entorno ${ }^{1}$ (Savirón, 1875, 129; Fernández de Avilés, 1949, 58). Estas noticias debieron de trascender en los círculos de eruditos y aficionados, puesto que Lasalde $(1879,1)$ indica que en 1859 estuvo allí el presbítero valenciano F.J. Biosca $^{2}$.

1. El hallazgo de esculturas en piedra en esta pequeña elevación, situada junto a la «cañada de Yecla», a $8 \mathrm{~km}$ de Montealegre del Castillo (Albacete) (Fig. 1), ha sido una constante durante siglos. Su denominación como «Cerro de los Santos» aparece ya en ciertos documentos del Conde de Montealegre que se remontan al s. XV (López Azorín, 1994, 60). Por su parte, Losa Serrano $(1998,55)$, en su estudio sobre el Señorío de Montealegre, localiza también este topónimo en los archivos correspondientes a un deslinde con la vecina población de Yecla que se llevó a cabo en 1526.

2. Este autor no se centraría en la publicación de algunos de sus restos hasta bastante más tarde, cuando ya eran un tema bien conocido entre anticuarios y arqueólogos (Biosca, 1873). 

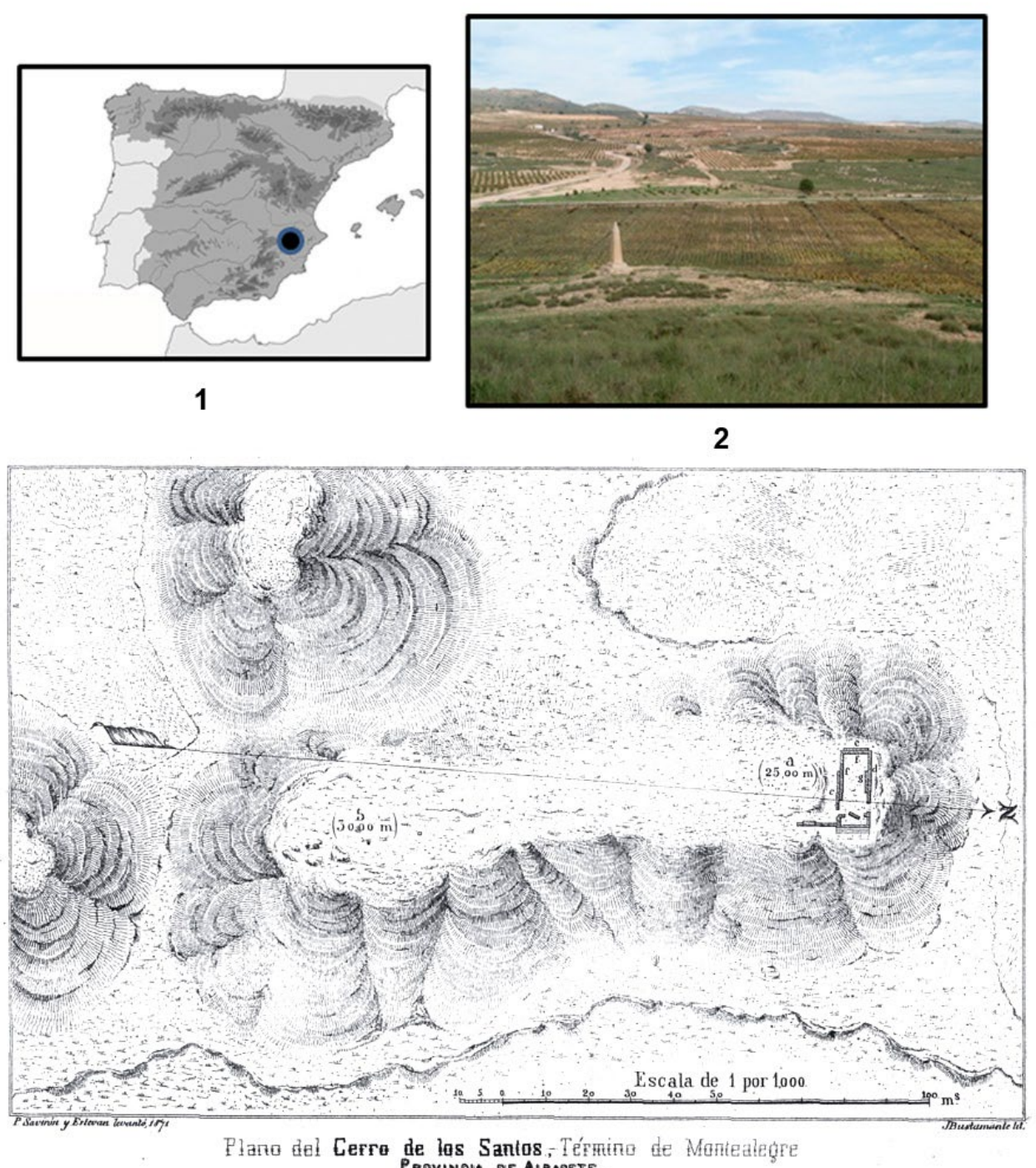

Provincia de Alabete.

Figura 1: 1. Localización del Cerro de los Santos. 2. Vista del Cerro sobre la Cañada de Yecla. El monolito indica el lugar del antiguo templo. 3. Plano del yacimiento realizado por Savirón (1875).

Fue un año después, en 1860, cuando el mundo académico fue advertido de la existencia del yacimiento y de sus singulares características, tras la visita de Juan de Dios Aguado y Alarcón, vecino de Corral Rubio. Este momento, clave para el conocimiento del Cerro de los Santos, marca también el inicio de los datos confusos y a menudo contradictorios sobre este lugar. La diversidad de informaciones existente sobre la fecha concreta de esta visita y su posterior notificación, con datos y dibujos, a la Real Academia de San Fernando, resulta sorprendente. Mélida (1903b, 474) la sitúa el 28 de enero y la notificación el 31 del mismo mes. Amador de los Ríos (1863, 13), siguiendo aparentemente ciertas indicaciones de Aguado, habla de «los primeros meses». Pierre Paris (1903, 43, nota 1) revisó un cuaderno del propio Aguado, entonces en poder de Pascual Serrano, profesor de Instrucción Pública de Bonete, en el que había una nota manuscrita del autor afirmando que había enviado la notificación a la Academia de Bellas Artes el 28 de junio, lo que indica que su presencia en el Cerro tuvo que ser anterior. Rada y Delgado $(1875,12)$ y Engel $(1892,158)$ fechan la visita al Cerro un mes después, el 28 de julio. Sin embargo, el propio Aguado publicará en 1875 que, estando tremendamente interesado en las noticias que había recibido sobre el yacimiento y tras acabar las tareas agrícolas que le ocupaban en el cercano pueblo de Corral Rubio, "... los últimos días del mes de agosto invité a mis apreciables amigos D. Juan José Guillén y D. Jose Ramón Mancebo para llevar a cabo la tan por mí deseada expedición» (Aguado y Alarcón, 1875, 3 ). Por entender que no le correspondía actuar en este caso, la Real Academia de San Fernando remitió el expediente a la de la Historia el día 29 de octubre de 1860, cuya contestación agradeciendo el envío data de 2 de noviembre (Maier, 1999, 29). Así pues, cualquiera de las fechas propuestas anteriormente para el envío de la documentación original desde Corral Rubio 
puede ser válida, aunque la justificación de Aguado respecto al término de la cosecha hacen más probables las de finales de junio o julio.

Amador de los Ríos $(1863,13)$ parece haber sido el único que manejó el cuaderno enviado por Aguado a Madrid, e incluso debió tener una entrevista personal con él, en la que pudo obtener datos respecto al Cerro y el paisaje de su entorno "del cual no tendríamos noticia alguna sin el ilustrado celo del joven D. Juan de Dios Aguado y Alarcon, quien no sólo ha remitido los diseños con que procuramos ilustrar las presentes lineas, sino que pasando á esta capital, nos ha facilitado cuantas noticias topográficas habiamos menester, para formar concepto de lo que era y significaba el edificio ya destruido en el Cerro de los Santos». Desgraciadamente estos documentos originales se debieron perder pronto, puesto que Rada ya indica en su discurso de entrada a la RAH que no pudo localizarlos (Rada y Delgado, 1875, 20). Como se ha señalado, Aguado conservó en su poder unos originales que pasaron a la colección de P. Serrano y que llegaron a ser consultados en Bonete por P. Paris (1903, 43), pero desconocemos si esta documentación se conserva.

Las visitas al Cerro debieron menudear en estos años (Fernández de Avilés, 1949, 59), aunque solo se documenta la de un cantero y escultor francés que extrajo una figura femenina sedente, trasladándola a Yecla ${ }^{3}$. Esta noticia la recoge Giménez Rubio (1865, 46-47), quien debió ver la estatua, ya que en su opinión «Parece ser imitación de una momia egipcia por el aire de su traje y aptitud; aunque por su aspecto, collares y enormes arracadas, podrá ser también un ídolo del gentilismo». En esta misma obra sobre la Historia de Yecla, Giménez Rubio describe además las características de los hallazgos que proporcionaba el Cerro, lo que confirma el conocimiento general de este yacimiento antes de las excavaciones de 1871, «Se encuentran en el mismo punto con profusión, fragmentos de estatuaria antigua con aire egipcio en las figuras y principalmente griego. Diferentes de capiteles, pilastras y otras curiosidades, pero todo truncado y enteramente deteriorado» (Giménez Rubio, 1865, 47). En todo caso, numerosos particulares debieron guardar restos escultóricos del Cerro en sus domicilios, siendo luego comprados muchos de ellos a medida que se conocía el valor económico e histórico que podrían llegar a alcanzar.

Este primer capítulo de la historia del Cerro de los Santos se cierra con la ya citada publicación de Amador de los Ríos (1863), en la que se ofrece una descripción topográfica y del estado de sus ruinas, siguiendo

\footnotetext{
3. Puede que este personaje tuviera que ver con las falsificaciones con las que traficó más tarde Vicente Juan y Amat, como ya se ha sugerido (Ruiz Molina, 2005, 204; López Azorín y Ruiz Molina, 2007, 65) basándose en la comprobación del padrón de Yecla en esos momentos. En él solo figura una persona de nacionalidad francesa, llamada Carlos Bollier. Su profesión era la de picapedrero, por lo que encajaría en el perfil de supuesto falsario vinculado a V. Juan y Amat.
}

las indicaciones de Aguado y Alarcón, e incluyendo sus dibujos en una lámina. Su interpretación del santuario como un Martyrium cristiano de época visigoda no se alejará de las de otros autores, que mantendrán esta propuesta cronológica dentro de la Antigüedad tardía (Rada y Delgado, 1875).

La segunda etapa se inicia en 1870 , aunque no nos alargaremos aquí con la secuencia ni los detalles de las actuaciones que tuvieron lugar a partir de este momento en el Cerro, puesto que han sido descritas con detalle por Savirón (1875), Mélida (1903-1905), Fernández de Avilés (1949), Ruano (1987), Ruiz Bremón (1989), Lucas (1994), López Azorín (1994) o Sánchez Gómez (2002). La obra primordial de la que arranca toda la investigación fue indudablemente la Memoria sobre las notables excavaciones hechas en el Cerro de los Santos, publicada en 1871 por los PP. Escolapios de Yecla sin especificar autoría, aunque se sabe que fue redactada por Tomás Sáez del Caño, Manuel Gómez y Carlos Lasalde (López Azorín, 1994, 83). Este trabajo llegó al Museo Arqueológico Nacional poco después de su aparición, y provocó que se formase ese mismo año la comisión oficial que debía ir a Yecla a investigar y adquirir piezas que fueran interesantes para el Museo (Mélida, 1903b, 470). Son precisamente estas primeras adquisiciones y los resultados de las excavaciones en el Cerro las que interesan a nuestro estudio, puesto que la Exposición Universal de Viena se celebraría solo dos años después.

El primer viaje se llevó a cabo en septiembre de 1871, resultando comisionados J.A. Malibrán y P. Savirón, funcionarios del Museo Arqueológico. En esta ocasión no se llegó a trabajar en el yacimiento, adquiriéndose 50 restos escultóricos a Vicente Juan y $\mathrm{Amat}^{4}$. Un mes más tarde, la segunda Comisión, constituida por el director del Museo, V. Ruiz Aguilera, y de nuevo por P. Savirón, volvió a comprar un lote de 50 esculturas a Amat, acompañándolas de diversos tipos de objetos de su colección, procedentes tanto del Cerro de los Santos como de otros lugares de Albacete y Murcia (Mélida, 1903b, 471). Antes de la celebración de la Exposición Universal de Viena se adquirieron otras colecciones a Amat en enero y mayo de 1872 (López Azorín, 1994, 371-373), así como treinta esculturas al anticuario Miró, entre las que se encontraba la Gran Dama Oferente, ingreso que se produjo en enero de 1873 (Mélida, 1905b, 35; López Azorín, 1994, 123). A estas compras se unieron parte de las piezas directamente obtenidas en el yacimiento por la Comisión del Museo Arqueológico Nacional en 1871, las adquisiciones realizadas a diversos propietarios del entorno del Cerro y algunas donaciones (Savirón, 1875, 229-233). Por tanto, antes de la Exposición

4. Las diferentes adquisiciones a V. Juan y Amat han sido detalladamente recogidas por López Azorín (1994, 178 y 2011, 283) mediante consulta de los archivos del Museo Arqueológico Nacional. 
Universal de Viena, el Museo contaba con una amplia colección de esculturas, si bien la entrada de materiales siguió activa en los años posteriores, elevándose aproximadamente a 300 las piezas que formaban la colección cuando J. R. Mélida (1903b, 474) realiza su pormenorizado estudio distinguiendo las auténticas de las falsas.

No hay que olvidar que el viaje de las Comisiones y los primeros ingresos de esculturas y otros materiales se desarrollaron en 1871, un año de una actividad frenética para el Museo. Además de las noticias sobre el Cerro de los Santos, se recibieron otras de diversos lugares de la Península, a las que también se atiende con desplazamiento de los funcionarios (Mélida, 1903b, 470; Franco, 1993, 304-6). En las mismas fechas tuvo lugar igualmente la conocida expedición de la Fragata «Arapiles», que aportó al Museo una interesante colección mediterránea. Mientras tanto, la institución debió prepararse para una estratégica inauguración oficial por Amadeo I de Saboya el 9 de julio (Marcos Pous, 1993, 57). A pesar de la extraordinaria profesionalidad de los funcionarios, todas estas circunstancias provocaron que en este primer momento el inventario de las piezas no fuera exhaustivo (Mélida, 1905b, 32) y así, el primer Catálogo del Museo (García Gutiérrez, 1876,62 ) sólo recogía que el gabinete de las «antigüedades de Yecla» incluía 244 piezas, entre estatuas y fragmentos, acompañados de otros materiales recuperados en el antiguo santuario.

El Museo Arqueológico Nacional consiguió, gracias a estas adquisiciones, una mayor presencia nacional e internacional. El Emperador del Brasil realizó una detallada visita en febrero de 1872, "quedando muy satisfecho y aun sorprendido de las numerosas colecciones artísticas que en aquel establecimiento se custodian, y principalmente de los objetos traidos de Yecla, que tienen hoy el privilegio de llamar la atención de cuantos se interesan por los estudios arqueológicos» ${ }^{5}$. Consta también la presencia de arqueólogos conocidos, como conservadores del Museo Británico, o el propio A. H. Layard, entonces embajador británico en España y con amplia experiencia arqueológica por sus excavaciones en Nínive (Miranda Valdés, et al., 2011, 171). Todos ellos apreciaron significativamente estas colecciones, pero sin aportar interpretaciones que permitieran aclarar su filiación cultural. Estas circunstancias movieron a los responsables de la institución a buscar otras vías de difusión internacional para las esculturas del Cerro.

\section{LOS VACIADOS DEL CERRO DE LOS SANTOS EN LA EXPOSICIÓN UNIVERSAL DE VIENA}

La convocatoria de una Exposición Universal, que se celebraría en Viena entre el 1 de mayo y el 31 de

5. Gazeta de Madrid, Año II, $\mathrm{n}^{\circ}$ 4, 29 de febrero de 1872, 54. octubre de 1873, supuso tanto una oportunidad como un gran reto. Tras la Revolución de 1868, y en el régimen de monarquía parlamentaria encabezado por Amadeo I, el gobierno considera que España «debe concurrir presurosa a ocupar el puesto de honor que... se le designa, y a demostrar el grado de prosperidad y cultura a que rayan su industria, sus artes y sus conocimientos cientificos». Subraya que el interés por acudir a la Exposición queda reforzado por los criterios serios y científicos que la comisión imperial austro-húngara ha aportado a la hora de organizar dicha muestra. Siguen a esta presentación los decretos reales organizando la participación española y nombrando a la comisión regia, presidida por D. Manuel de la Concha, Marqués del Duero ${ }^{6}$.

El comisario imperial fue el barón Guillermo de Schwarz-Senborn, quien tenía una larga experiencia internacional y ya había ocupado este puesto en las exposiciones de Paris (1855) y Londres (1862) (Reuleaux, 1891, 188-189). La intención general era mostrar los avances de las artes, la industria y la cultura en todos sus ámbitos, dividiendo ordenadamente sus contenidos en 26 grupos bien definidos. En ellos se distribuían entre otros, la minería, todos los tipos de producciones industriales, la ingeniería civil y militar, las bellas artes y el arte religioso, la vivienda y la educación, con un apartado específico relacionado con el trabajo de la mujer. Por primera vez en este tipo de acontecimientos, más pensado para establecer las novedades del presente y sus posibilidades futuras, se abrió una sección dedicada a las antigüedades. Su objetivo era precisamente resaltar el peso que habían tenido en el desarrollo industrial y cultural de la época moderna, y para ello se especificaba que «este apartado debe contener todo lo más notable de las obras más perfectas y características del pasado a fin de poder demostrar la parte que estos elementos han tomado en su desenvolvimiento en las diferentes épocas anteriores». Era este el Grupo 24, «Objetos artísticos e industriales del antiguo expuestos por aficionados y coleccionistas», también denominado «exposición de aficionados (amateurs)»? .

Podemos imaginar el trabajo ingente que supuso la organización de los materiales que se desplazaron a Viena, aportados por instituciones oficiales y privadas, así como por numerosísimos particulares de toda la geografía española. Entre ellos estaban las piezas

6. Tanto la exposición de intenciones como los decretos de Amadeo I tienen fecha de 19 de abril de 1872, publicándose en la Gazeta de Madrid de 21 de abril (Año CCXI, n ${ }^{\circ} 112$, tomo II, 199).

7. Gazeta de Madrid no 312 (7 de noviembre de 1872), 394. La inclusión de las antigüedades sorprendió bastante. En La Ilustración Española y Americana (1873, n ${ }^{\circ}$ XXXVI, 590) una opinión anónima afirma que los objetos arqueológicos fueron enviados por el gobierno español y muchos particulares «en cumplimiento del programa que convocó a Viena esta curiosa materia de exposición». 
que seleccionó el Museo Arqueológico Nacional, correspondientes a sus colecciones españolas y americanas $^{8}$. La reciente incorporación al Museo de las esculturas del Cerro de los Santos y la novedad histórico-arqueológica que suponían, animó a presentarlas en este contexto internacional, pero no se consideró oportuno enviar piezas originales, seguramente por el riesgo que podrían sufrir en su traslado y exposición. Por ello se recurrió al sistema de los «vaciados» en yeso o escayola, proceso que se activó con rapidez, dada la cercanía de las fechas del viaje a Viena ${ }^{9}$. Con tal fin, el Ministerio autorizó al director del Museo a «remitir á la exposición de Viena los objetos de aquel establecimiento que considere dignos de figurar en la misma. También se ha resuelto se vacien las estatuas procedentes de Yecla, si, a juicio del mismo jefe, puede hacerse esta operación sin que padezcan el valor $y$ mérito de aquéllas ${ }^{10}$. Esta operación dio como resultado los primeros vaciados, calificados por García Gutiérrez $(1876,19)$ como «exactísimos».

El Archivo del Museo Arqueológico Nacional, en el «Expediente de Viena» incluido en la carpeta del Cerro de los Santos, conserva el listado de las piezas que se desplazaron ${ }^{11}$. Textualmente dice lo siguiente,

\begin{abstract}
"Obgetos del Cerro de los Santos
Catorce vaciados de estatuas procedentes de los descubrimientos hechos en el Cerro de los Santos, cerca de Yecla, territorio de la provincia de Albacete, de las cuales dos aparecen sentadas y las restantes en pié, con diversos atributos y vestiduras. $N^{o}{ }_{1}$ al 11,13 y 14 .

- Grupo id. de dos estatuas enlazadas, en pié. $N^{\circ} 12$.

- Parte superior de estatua con mitra de figura trapezoidal invertida. $N^{o} 15$.
\end{abstract}

8. Organizadas en 53 lotes, recibieron los números 1472 a 1525 del registro general, y 2770 a 2823 del depósito. Otras piezas, como dos candelabros y una cruz parroquial también enviadas por el Museo Arqueológico, se inventariaron en el registro general con los números 1632-3 (13 y 14 del primer apéndice en el Depósito) (La Gazeta de Madrid, 12 de agosto de 1873, $\left.n^{\circ} 224,1347-1348\right)$.

9. La importancia de los vaciados en esta época ha sido tratado por S. González Reyero (2006: 347-353)

10. RABM Año III, no 6 de 1873 (Marzo), 86. Durante la dirección de José Amador de los Ríos (10 de febrero a 17 de noviembre de 1868), se construyó en el Jardín del Museo un pequeño taller de restauración, que el siguiente director, Ventura Ruiz Aguilera, decidió ocupar en 1871 con las colecciones de Prehistoria, debido a la escasez de espacio en el edificio principal (García Gutiérrez, 1876, 15; Marcos Pous, 1993, 44 y 56). En todo caso, seguramente los vaciados se realizaron en la propia institución.

11. Según consta en la Gazeta de Madrid ( $n^{\circ} 224,14$ de agosto de 1873,1347$)$, las piezas enviadas fueron 14 , cantidad que no encaja con el listado incluido a continuación. El error procede de la omisión de parte del primer párrafo que consta en el inventario del M.A.N. (Expediente de Viena, Objetos del Cerro de los Santos. 1874.19).
- Parte superior de estatua sin cabeza, embozada en un manto. $N^{\circ} 16$.

- Parte superior de estatuita con dos rosetones en las sienes. $N^{\circ} 17$

- Estatua sin cabeza; en la mano derecha un vaso y en la muñeca una especia de ¡estola? $N^{o} 18$.

- Cabeza de tamaño mayor que el natural, cubierta por un casquete. $N^{\circ} 19$.

- Cabeza con ornato y mitra. $N^{o} 20$.

- Cabezas varoniles mutiladas. $N^{\circ} 21$ y 22 .

- Plinto con cabeza bifronte. $N^{o} 23$.

- Rinoceronte. $N^{\circ} 24$.

- Toro sin cabeza, con inscripción en el plinto. $N^{o}$ 25.

- Fragmento alegórico con un cordero y un niño. $N^{\circ} 26$.

- Monstruo de tres cabezas y parte inferior de una figura humana. $N^{\circ} 27$.

- Obelisco con representaciones simbólicas o jjeroglificas?. $N^{\circ} 28$.

- Vaso con un busto y adornos. $N^{\circ} 29$.

- Lápida con caracteres celtibéricos, hallada cerca de Valencia. $N^{o} 30$.

Total, 30 vaciados.

Nota, En el cajón $n^{\circ} 1$ de esta primera sección va la estatua grande de Yecla; en el $n^{\circ} 2$ otra estatua, las 13 hachas de piedra, las 7 de cobre y bronce y las cuatro espadas. En los restantes cajones las demás estatuas y obgetos de Yecla».

En la siguiente tabla (Fig. 2) se intenta correlacionar la lista anterior con las piezas cuyos vaciados fueron enviados a Viena. En algunos casos la identificación es clara, mientras que en otros existen dudas, debido al carácter excesivamente genérico de su descripción, por lo que proponemos las posibilidades que nos parecen más razonables.

Aunque la organización austríaca había previsto la llegada de las piezas de los distintos expositores internacionales entre el 1 de febrero y el 15 de abril, con objeto de que pudieran ser acomodadas en sus respectivas sedes antes de la inauguración oficial, pocos pudieron cumplir este objetivo. Como señala Reuleaux (1891, 191-192), «El 1 1 de Mayo de 1873, el emperador inauguraba la Exposición, por no faltar a la costumbre estatuida en las anteriores, de verificar el acto de apertura el día señalado, aunque estuviese sin concluir el edificio, sin clasificar, ordenar ni poner en sus instalaciones los objetos que se habian de exponer; $y$, en efecto, algunos días después de la apertura el Comisario regio cerró las puertas de la nave central, por la razón sencilla de que ni en ésta ni en las otras habia nada expuesto, y casi todo el palacio estaba por concluir». La colección española no debió retrasarse mucho, puesto que un grabado de La Ilustración Española y Americana, publicado el 14 de abril, refleja la salida de las cajas de embalaje (Fig. 3).

A pesar de todo, en el caso español, la situación se agravó considerablemente una vez en Viena, al encontrar serias dificultades para la construcción del pabellón de estilo mudéjar que se había planificado. 


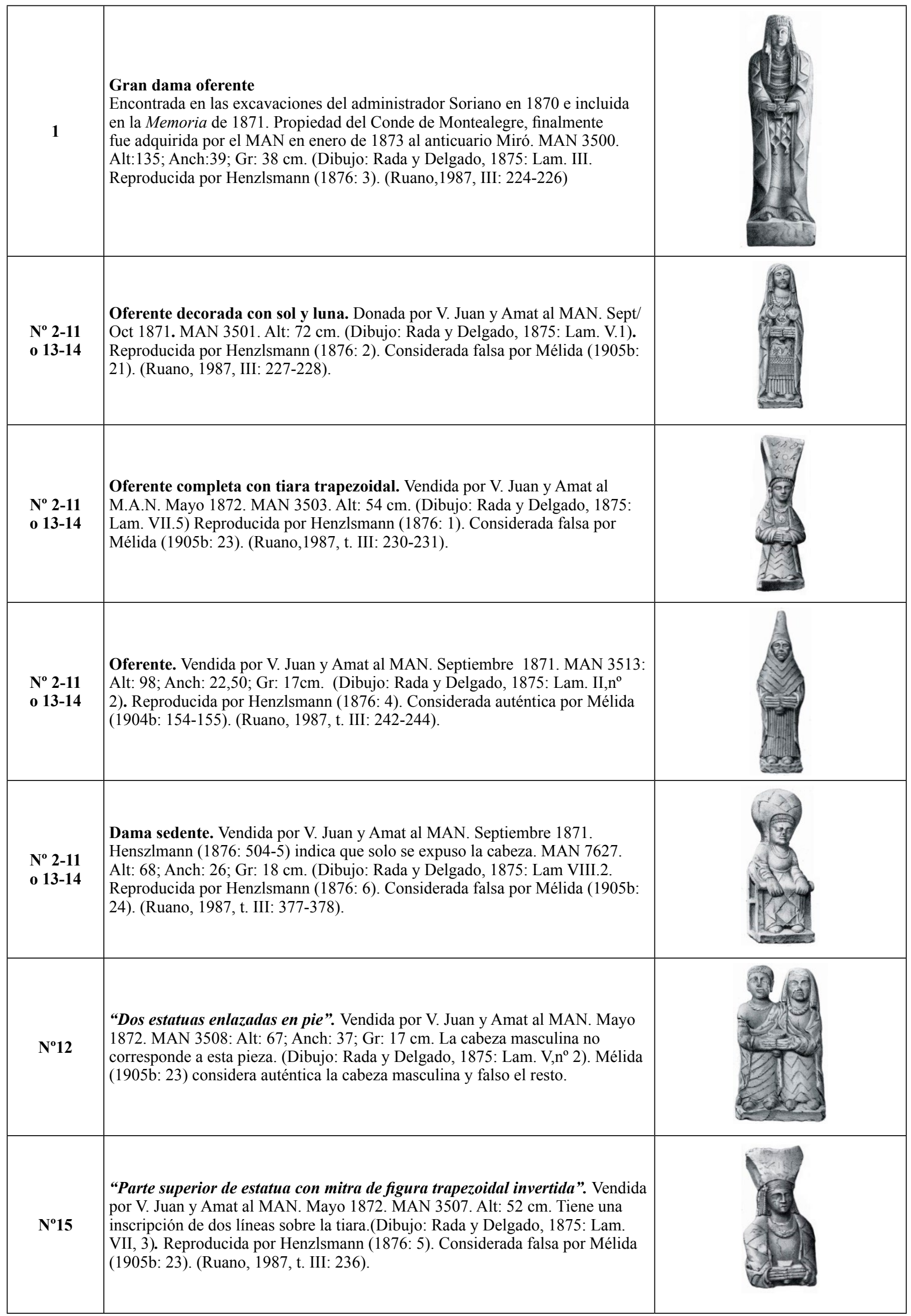




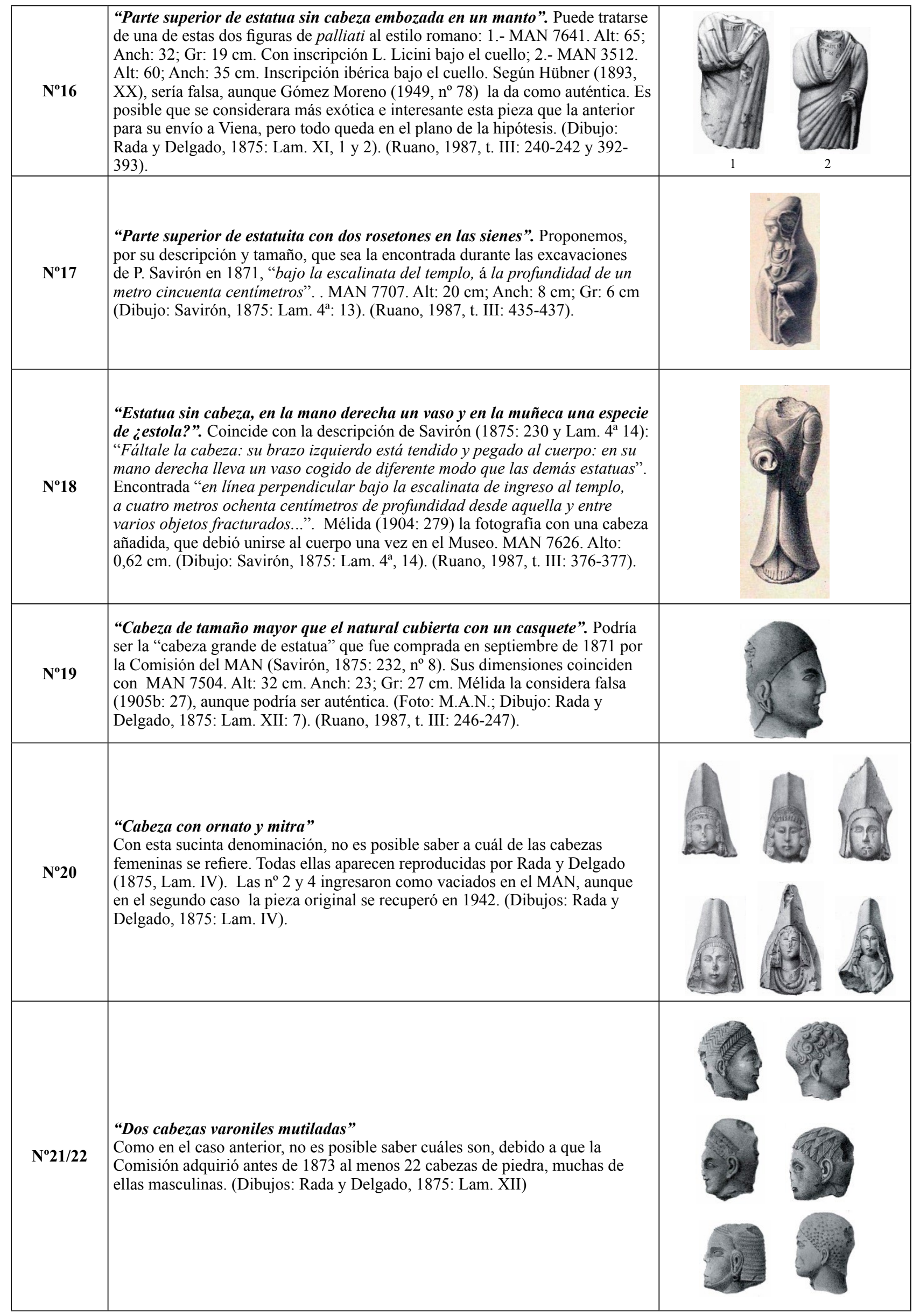




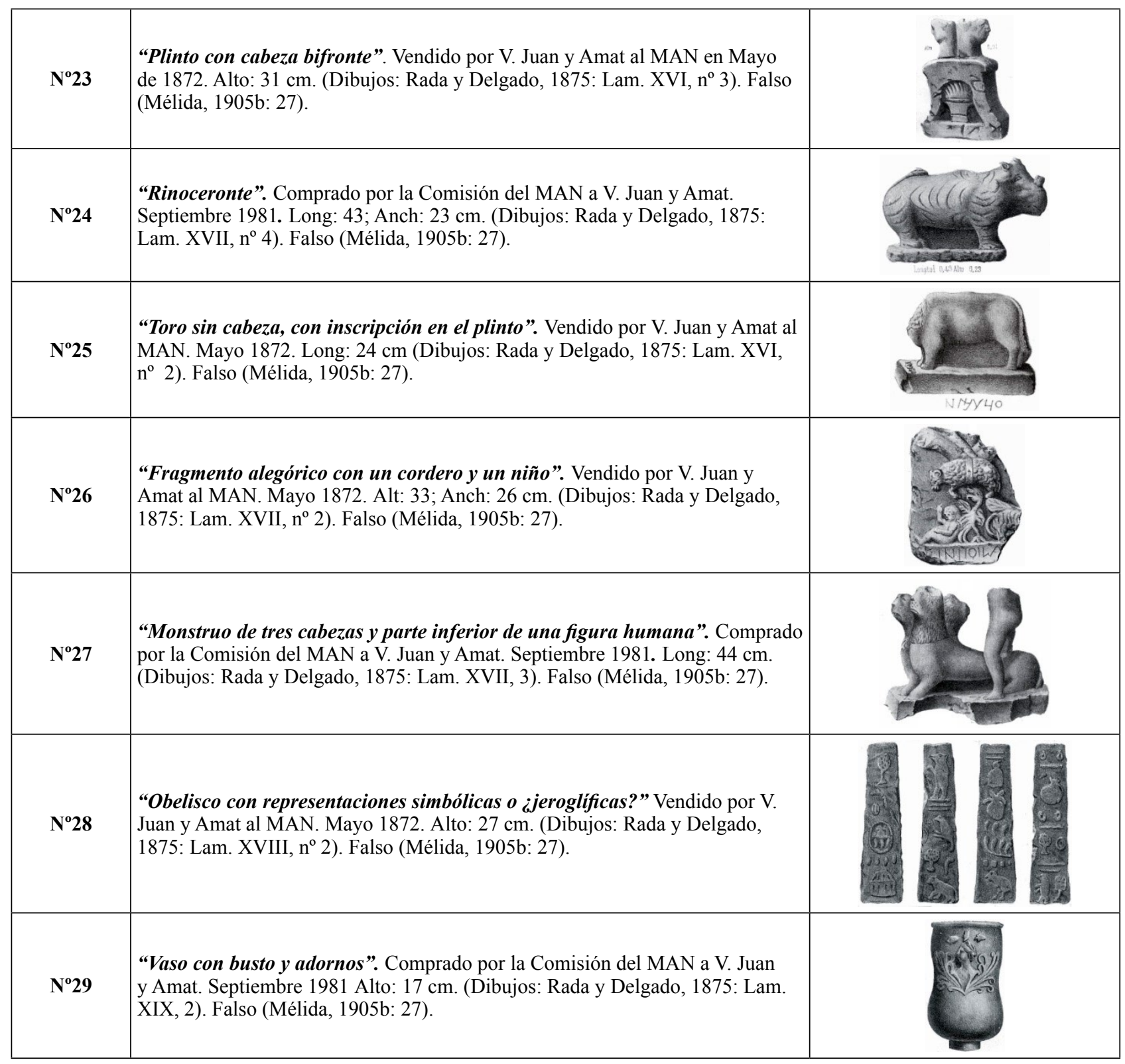

Figura 2: Esculturas cuyos moldes fueron enviados a Viena. Algunas se han identificado por su inclusión en el estudio de Henszlmann (1877) y otras por su referencia en la lista de piezas (incompleta) publicada en La Gaceta de Madrid (nº 224, 14 de agosto de 1873, 1347).

El edificio, tal y como fue proyectado por Lorenzo Álvarez y Capra, tenía forma de $\mathrm{H}$, accediéndose por una escalinata central. Coherente con el estilo, el material constructivo debía ser el ladrillo, pero a la comisión le resultó imposible conseguir a tiempo ni los materiales ni los medios para llevar a cabo la construcción conforme a los planes previstos, de forma que tuvo que aceptar que el edificio se levantara en madera, confiando en que los revestimientos exteriores disimularan la ausencia del ladrillo. La precipitación y la falta de adecuación de los materiales incidieron muy desfavorablemente en la obra, provocando retrasos que impidieron la colocación de los expositores hasta casi dos meses después de inaugurada la muestra (Navarro Reverter, 1875, 236) ${ }^{12}$.

12. «Como cosa de España, empezóse tarde, costó caro y se acabó mal, sin que realmente pueda culparse a nadie por ello. Mediaba ya la duración del certamen, y el Jurado terminaba sus trabajos, cuando el muzárabe edificio se remataba. El remate se realizó en malas condiciones, con el yeso húmedo. Las lluvias rajaron las maderas, el edificio además, no sé si por efecto del proyecto o por no estar ajustado a los planos, resultó harto pequeño; la escalera para subir al piso principal, poco holgada, y con la falta de decoración desairadas todas las piezas» (Navarro Reverter, 1875, 293-294) 


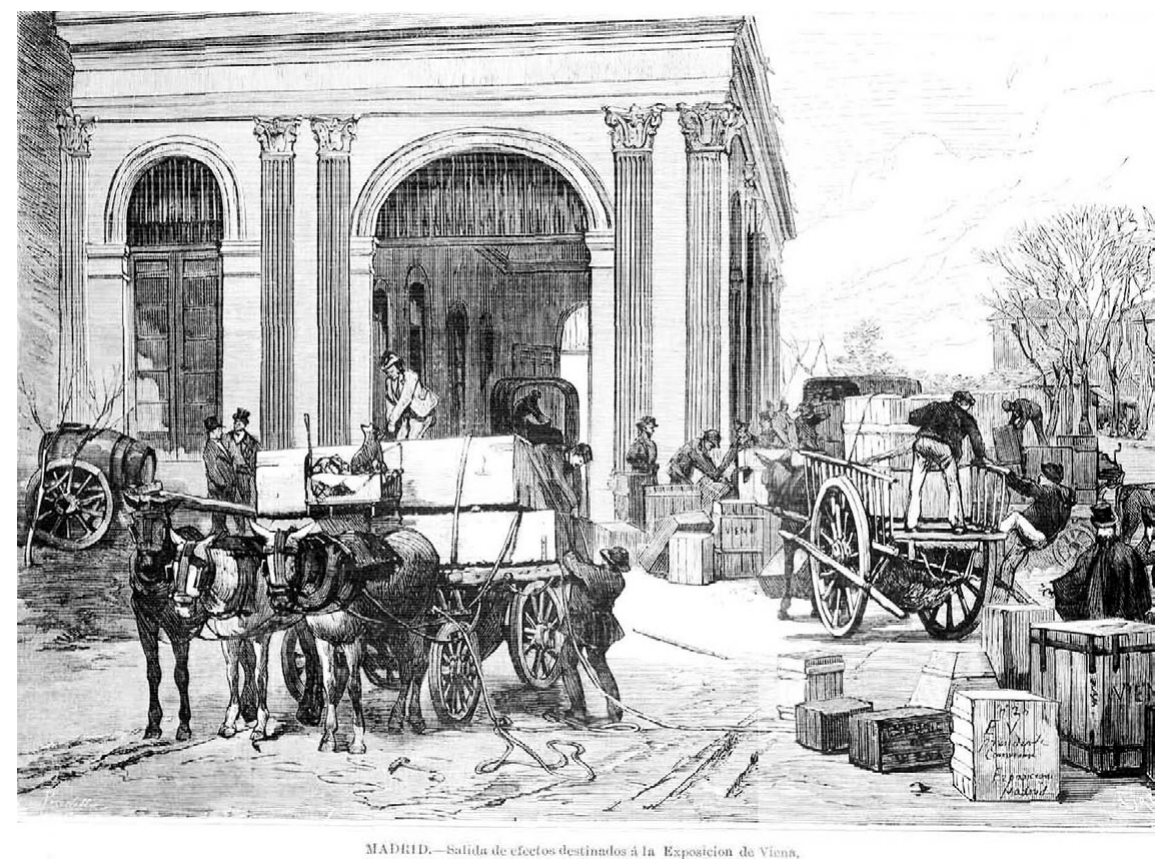

Figura 3: Madrid. Salida de embalajes hacia la Exposición de Viena. Grabado de La Ilustración Española y Americana (Año XVII, $\mathrm{n}^{\circ}$ $\mathrm{XV}, 16 / 04 / 1873,257)$.

Las diferencias entre lo proyectado y lo construido pueden apreciarse en los grabados publicados por La Ilustración Española y Americana (Fig. 4), pero parece que tanto el edificio como buena parte de lo que exponía fueron bien valorados finalmente en el contexto de la Exposición (Navarro Reverter, 1875, 294; La Ilustración Española y Americana $\mathrm{n}^{\circ}$ XLII de 8/11/1873, 675).

Sabemos que las antigüedades españolas se situaron en la nave central de la planta superior de este pabellón (Reuleaux, 1891,214), accediéndose a ellas desde la sala de arte militar. De nuevo, un grabado publicado por La Ilustración Española y Americana ${ }^{13}$, firmado por Laredo y Ovejero, es un excepcional testimonio que nos permite comprobar la situación de las estatuas del Cerro de los Santos (Fig. 5). Aunque centrado en la sala militar, el dibujo incluye a un visitante que se dirige a la siguiente habitación y, a través de la puerta, se insinúa con claridad la presencia de las primeras esculturas, al contraluz de los grandes ventanales de esta zona central del edificio (Fig. 6). Indudablemente en el dibujo se reconoce a la gran dama oferente, bien porque estuviera en ese sitio preciso o porque se quisiera reproducir la pieza más conocida de la colección, aunque lo primero es lo más probable.

El testimonio del arqueólogo húngaro M. Henszlmann que, como veremos, visitó y se interesó por el estudio de las esculturas, publicando incluso algunos dibujos de las mismas (Fig. 7), es importante para desvelar otro error de los documentos oficiales respecto a los hechos reales. Un particular de Yecla, D. Andrés de Espinosa, había enviado por propia iniciativa la

13. Año XVII, $n^{\circ}$ XLL ( $1^{\circ}$ de noviembre de 1873), 668.
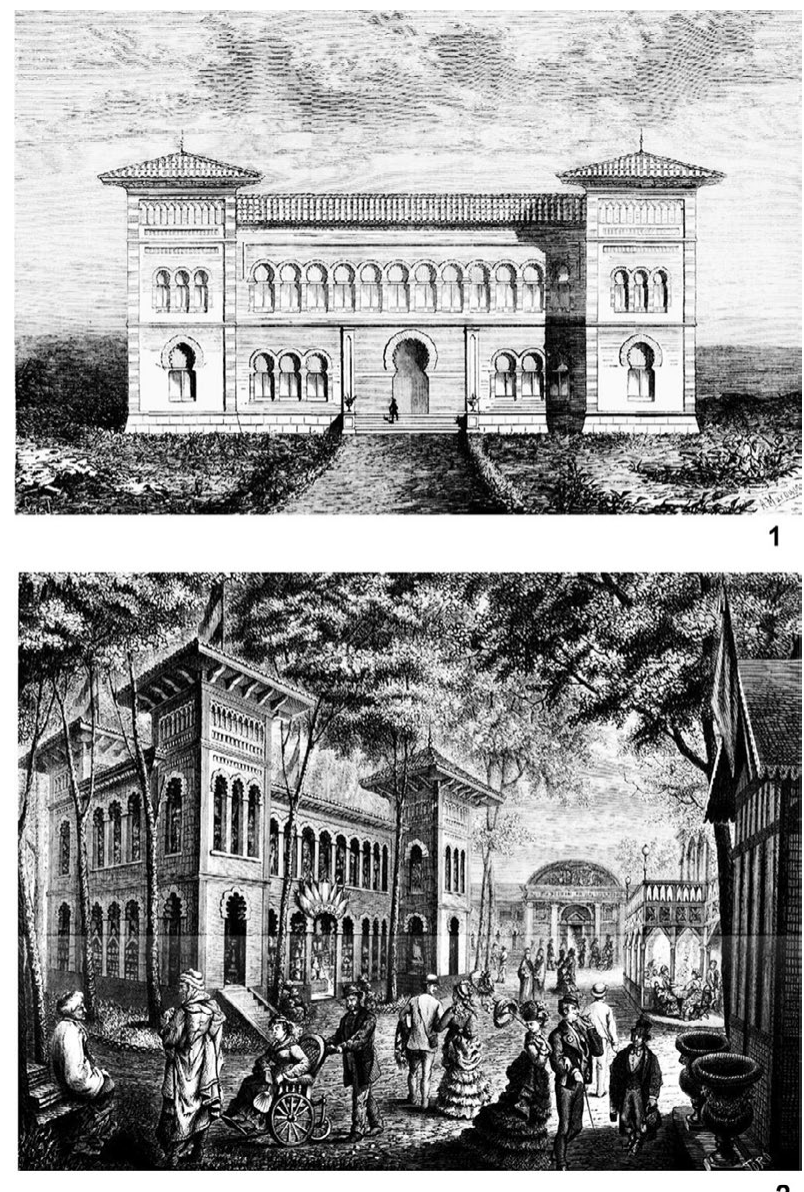

2

Figura 4: 1. Diseño original del pabellón de España en la Exposición Universal de Viena (La Ilustración Española y Americana, Año XVII, $\mathrm{n}^{\mathrm{o}}$ XXIII, 16/06/1873, 504). 2. Vista del pabellón ya construido (La Ilustración Española y Americana, Año XVII, $n^{\circ}$ XLII, 8/11/1873, 5). 


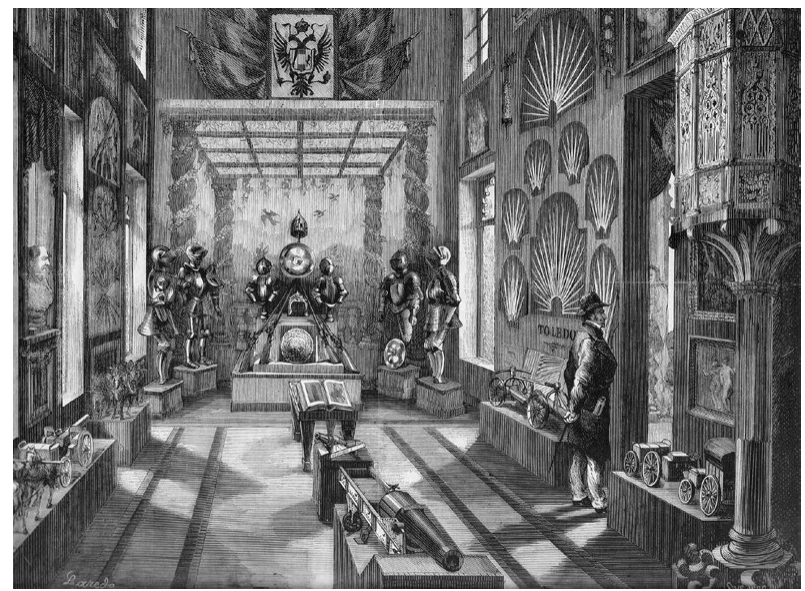

Figura 5: Vista general del piso superior del pabellón español con exposición de artes militares.

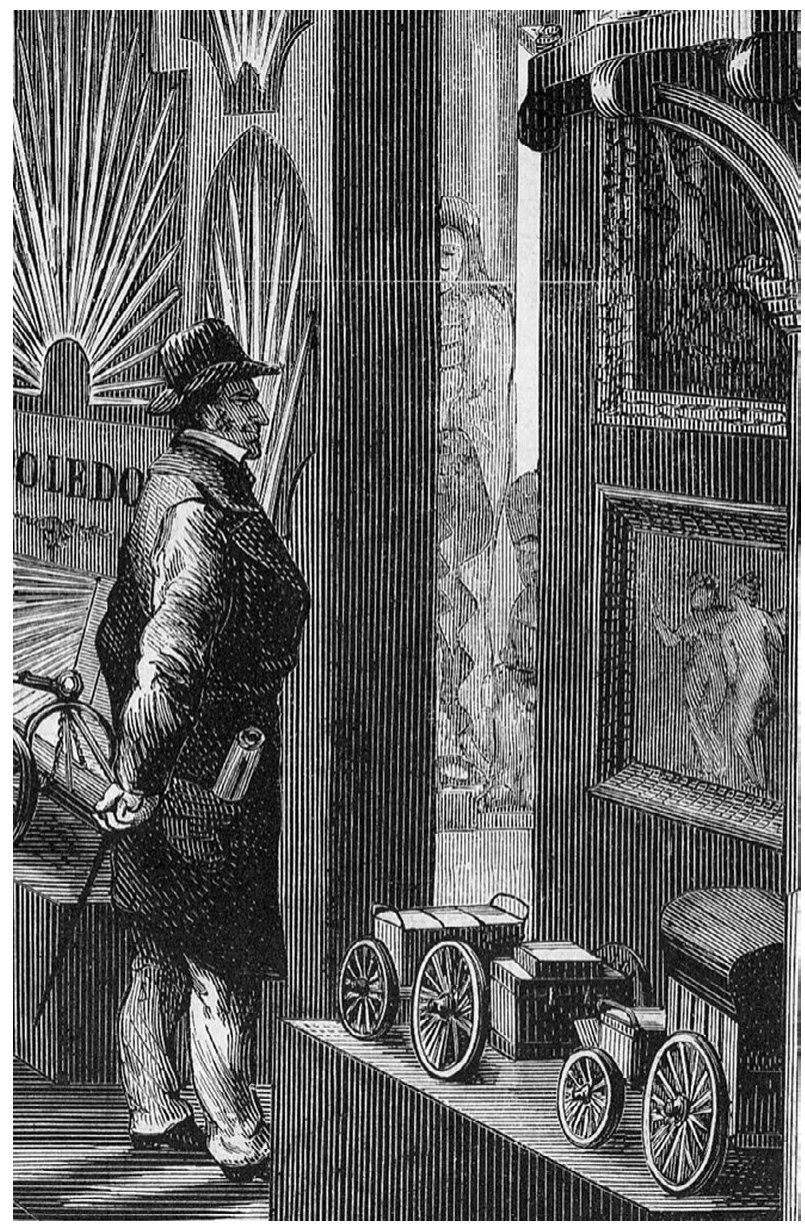

Figura 6: Detalle de la siguiente habitación, donde se aprecia la presencia de la Gran Dama Oferente (La Ilustración Española y Americana, Año XVII, nº XLI, 1/11/1873, 668).

Memoria de los PP. Escolapios (Memoria, 1871) para que figurase en la Exposición. Según el catálogo oficial de la sección española habría sido colocada en la sección de minerales de la planta baja (Commissariat, 1873, 49, nº 205 -4568-). Sin embargo, según Henszlmann $(1877,503)$, la Memoria estaba correctamente situada junto a las esculturas, «A l'exposition universelle de Vienne (1873), dans l'annexe de l'Espagne, on a pu voir quinze statues en plâtre... A côté il y avait un livre qui nous apprit le temps et la place de la trouvaille des originaux en pierre. Le titre de ce livre est, Memoria de las notables excavaciones hechas en el Terro de los Santos pobblicada par los P.P. Escolapios de Yecla. Madrid, 1871» [sic $]^{14}$.

Parece evidente que el esfuerzo por presentar la colección del Cerro de los Santos fue considerable y que el número de piezas seleccionadas fue amplio. Quizás guiado por la lista publicada en la Gaceta de Madrid (ver nota 10), donde no se recogía la mayor parte de las esculturas oferentes y sí muchas de las falsificaciones de Amat, Mélida (1903e, 366) afirmó que la selección de piezas había sido mala, pero lo cierto, como hemos visto, es que lo que realmente se envió fue bastante representativo de lo que era entonces la colección del Museo.

\section{VALORACIÓN CIENTÍFICA DE LAS ESCUL- TURAS DEL CERRO DE LOS SANTOS EN EL CONTEXTO DE LA EXPOSICIÓN DE VIENA}

Hasta 1873, las esculturas del Cerro de los Santos habían sido valoradas muy positivamente en España como muestras de un pasado monumental, aunque desconocido y necesitado de un adecuado estudio. La noticia publicada por Amador de los Ríos (1863) proponía interpretar este lugar como un templo cristiano de época visigoda dedicado a los mártires, contexto cronológico con el que coincidirían después a grandes rasgos otros autores, entre ellos Rada y Delgado (1875). Sin embargo, en este estudio el número de piezas analizadas era escaso, ninguna de ellas estaba completa y, como es lógico, carecían de extrañas simbologías, al no haber actuado todavía la imaginativa mano de Amat que tantos beneficios económicos y honoríficos sacaría de su intervención ${ }^{15}$.

Todo cambió cuando empezaron las excavaciones de 1870. En cuestión de meses se recogieron decenas de esculturas y la Memoria (1871) alertó a los

14. En la sala siguiente a la de las esculturas se acumulaban -hacinaban, en palabras de Navarro Reverter $(1875,299)-$ los documentos relacionados con la educación, y entre ellos no debemos olvidar los modelos caligráficos enviados por los propios Escolapios, por los que recibieron una medalla de mérito (López Azorín, 1994, Fig. 15).

15. «Deseando el Rey... ofrecer a D. Vicente Juan y Amat una prueba del aprecio con que ha acogido la generosa cesión hecha al Estado con destino al Museo Arqueológico Nacional...ha resuelto S.M. que en su Real nombre se den las gracias a dicho interesado y se haga público... este rasgo de patriótico desprendimiento» (Gazeta de Madrid, Año V, $\mathrm{n}^{\circ}$ 219, 7 de Agosto de 1875, 356). Al parecer, también se le llegó a conceder la Encomienda de Carlos III (López Azorín, 2011, 294). 

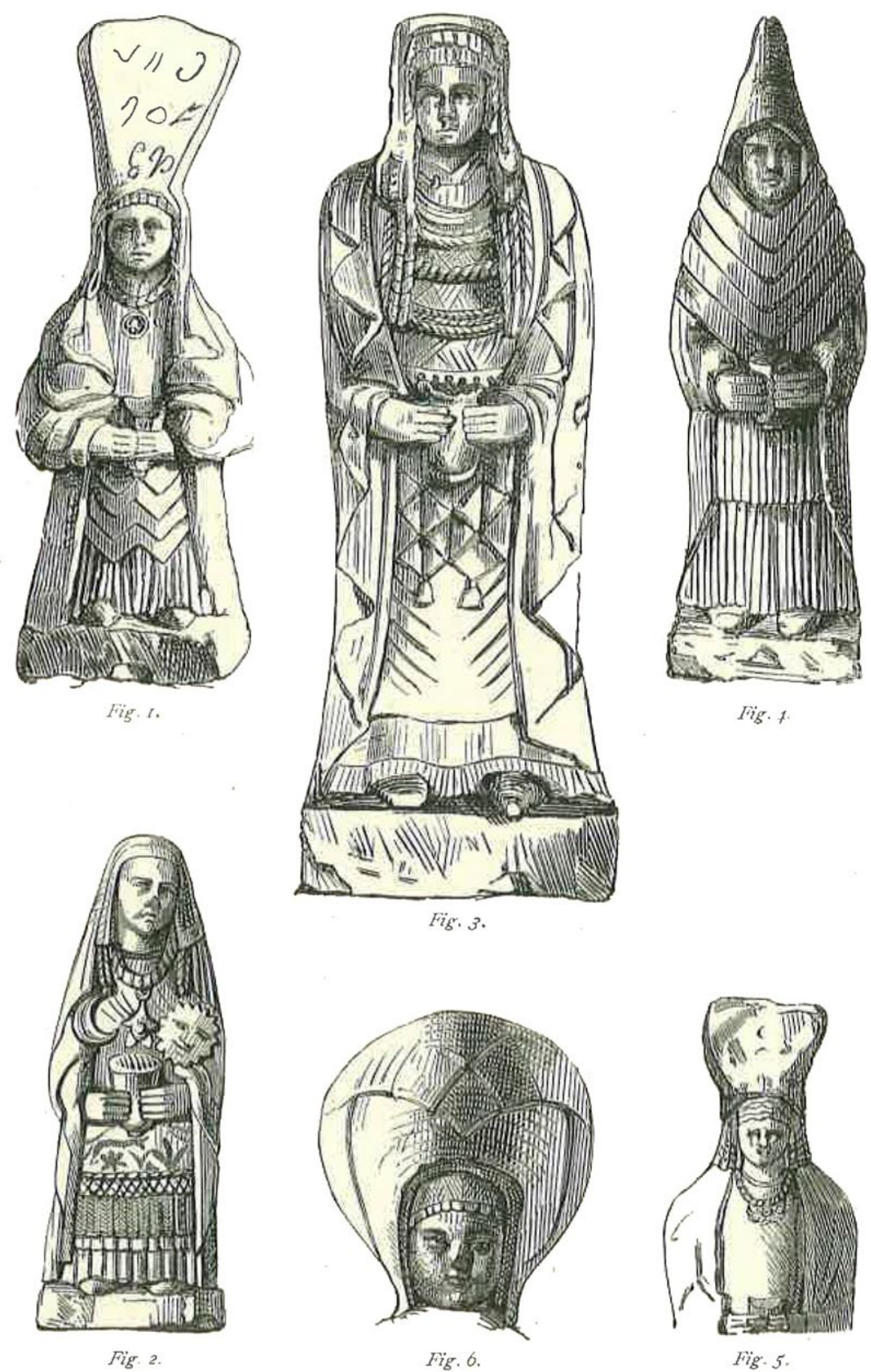

Figura 7: Dibujos de vaciados del Cerro de los Santos incluidos en el estudio de Henzlsmann $(1877,505)$.

funcionarios del Museo sobre la importancia de estos hallazgos. Como hemos visto, la rápida actuación de la administración consiguió recuperar un importante número de piezas para el Museo antes de la inauguración de la Exposición Universal, que luego seguiría completándose en los años siguientes. Se formó así una colección en la que figuraban tanto esculturas auténticas como falsas, aportando estas últimas un variado número de inscripciones «exóticas» que planteaban atractivos retos a la investigación epigráfica, especialidad de gran peso en la arqueología de la época.
Sin embargo, el mundo académico no se ocupó en estos primeros momentos de ofrecer una propuesta interpretativa del santuario del Cerro de los Santos, y su interpretación apenas salió del ámbito de la prensa (Sáez, 1870; Rentero Villota, 1871 a y b; Lasalde, 1871 a y b; Doménech, 1872). Tampoco se discutieron, al menos por escrito, ni las opiniones de Amador de los Ríos sobre su cronología visigoda, ni la de los PP. Escolapios sobre su adscripción al «pueblo bastitano» y su propuesta de destrucción por Aníbal a finales del s. III a.C. La opinión «académica» estaba aún por definir $\mathrm{y}$, probablemente por eso se consideró 

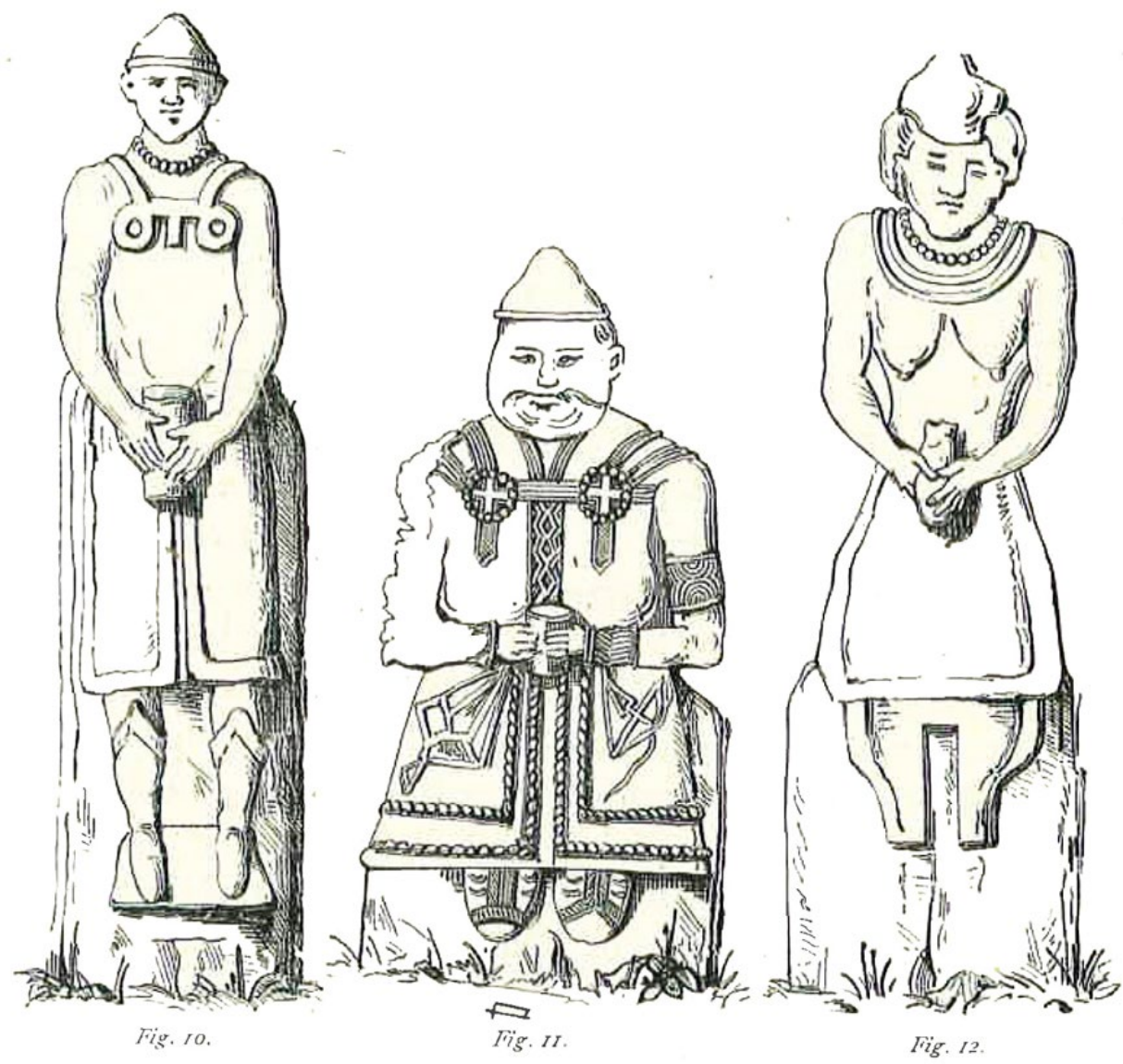

Figura 8: Esculturas de piedra denominadas «Kamennye-Baby» Henzlsmann $(1877,512)$.

una verdadera oportunidad el envío de una muestra a la Exposición Universal de Viena, donde especialistas reconocidos de ámbito internacional pudieran ver las copias y dar una fundamentada opinión.

Al finalizar la Exposición, el director del Museo, García Gutiérrez $(1876,19)$, subrayó el interés que las estatuas del Cerro habían despertado en los científicos extranjeros. Sin embargo, otros autores, con la perspectiva que da el paso del tiempo, han considerado que su estancia en Viena no significó ningún avance en el conocimiento e interpretación de esta colección (Olmos, 1999, 202). Esta era, desde luego, la opinión que se tenía en círculos ajenos al mundo especializado y Reuleaux $(1891,214)$, al citar los moldes de las esculturas en su crónica de la Exposición, afirma categóricamente que «su significación se ignora».

Sin embargo, la repercusión de los vaciados de las esculturas fue mayor de lo que en un principio podría pensarse, aunque quizás resulte menos conocida debido al ámbito geográfico de los investigadores que se ocuparon de ellas. Hay que resaltar aquí que durante el tiempo que duró la Exposición fue secretario de la Comisión Española S. Sanpere, quien estaba especialmente interesado en el estudio de las poblaciones prerromanas peninsulares (Sanpere, 1880a). Este erudito promovió activamente la visita de los arqueólogos extranjeros a las salas donde se exponían las copias del Cerro de los Santos, y de esta iniciativa surgirían los primeros intentos de relacionar las esculturas con otros contextos culturales.

La reacción más importante fue la del ya citado Henzslmann (1876, 506-518), a quien llamó la atención la actitud de las figuras oferentes, sujetando un vaso entre las manos a la altura del vientre. Tras buscar los paralelos iconográficos en Europa continental y Asia, se fijó especialmente en las esculturas, tanto masculinas como femeninas, llamadas «Kamennye Baby», que se situaban junto a los kurganes o túmulos funerarios construidos en territorios de Ucrania y todo el sur de Rusia entre los siglos VII y XII d.C (Pletneva, 1974; Kubarev, 2007) en época de los kaganatos túrquicos y uigures (Fig. 8). Teniendo en cuenta que estos monumentos se asignaban a los godos y dada la presencia de éstos en Hispania, consideró que las esculturas del Cerro serían de época visigoda, coincidiendo así sin saberlo y por razones totalmente independientes, con la opinión de Amador de los Ríos (1863). La asignación cultural de la producción escultórica al mundo de los godos permitía encuadrarla sin problemas en un marco difusionista. A esta corriente teórica, generalizada en la época, se unía el hecho bien documentado de los movimientos migratorios que terminaron con el Imperio Romano, lo que permitía 
considerar indiscutible la vinculación de las manifestaciones artísticas a través de extensos territorios (Baye, 2010).

Muchos especialistas conocieron a su vez las esculturas del Cerro de los Santos gracias al trabajo de Henzslmann, que trascendió a las sesiones de las academias y sociedades europeas, la vía más seria y segura de difusión de las novedades científicas en la época (Goodrum, 2009: 27). Así, Munch $(1878,197)$ las cita también en relación con las «Kamennye Baby», pero hace notar que conoce la Memoria de los PP. Escolapios y reproduce la división que estos hacen de las esculturas del Cerro en tres etapas, de acuerdo con la iconografía más o menos compleja de las figuras (Memoria, 1871, 102-104). Por su parte, Zaborowski $(1880)^{16}$ difunde en Francia las opiniones de Munch, y así llegamos al propio Cartailhac $(1886,303)$, quien de nuevo alude al trabajo de Henzslmann, aunque discrepando de su interpretación y proponiendo una cronología protohistórica para el yacimiento.

Como puede apreciarse, las esculturas del Cerro de los Santos habían sido conocidas y discutidas en diversos contextos académicos europeos, si bien en España esta vinculación entre los túmulos del sur de Rusia y las figuras oferentes de Albacete, propuesta originalmente por Henszlmann, no tuvo apenas repercusión. El único que parece haberse implicado personalmente en la refutación de esta hipótesis fue el ya citado S. Sanpere, quien extendió sus consultas a diversos arqueólogos rusos y alemanes, e incluso viajó a Moscú con este motivo, según recoge Mélida $(1903 d, 248)^{17}$.

\section{ENTRE VIENA Y PARÍS, EL DISCURSO DE RADA Y DELGADO}

Como hemos visto, al llegar a la Exposición de Viena, las esculturas del Cerro de los Santos constituían toda una novedad y no estaban mediatizadas por interpretaciones de peso académico. Desde luego, no provocaron la más mínima sospecha sobre su autenticidad entre los arqueólogos extranjeros que allí las conocieron. Sanpere $(1880 \mathrm{~b}, 174)$ hizo constar que de entre los muchos especialistas que las habían observado, «ni uno solo los estimó como fabricación moderna, todos o casi todos se limitaban a declarar que no sabian cómo explicar tales antigüedades». En cuanto a España, Mélida (1905b, 36) señala que «La existencia de piezas falsas en la colección no dio que sospechar

16. No hemos podido consultar este artículo (S. Zaborowski, 1880, «Les Kammenya-baby et les antiquilés du Cerro de los Santos». Revue Anthropologique, Julio) aunque Mélida (1903, 247) lo resume.

17. Parece que fue también Sanpere el que convenció a Cartailhac (1886) para incluir España en su estudio, que inicialmente sólo iba a centrarse en Portugal (Ayarzagüena, 1993, 408). hasta que el Sr. Rada publicó su Discurso». Cierto es que, ante la información que se iba difundiendo en Madrid sobre las compras hechas por los comisionados, ya se había dado algún toque de aviso sobre la dudosa procedencia de los objetos adquiridos (Sáez del Caño, 1871), pero apenas tuvo repercusión en la consideración de las esculturas.

En efecto, no sería hasta la publicación del discurso sobre las «Antigüedades del Cerro de los Santos en término de Montealegre», elaborado por Rada y Delgado para su entrada a la Academia de la Historia el 27 de junio de 1875, cuando la colección tuvo una presentación pública más relevante, aportando una documentación gráfica abundante y de calidad. La contestación del respetado A. Fernández-Guerra se centró en la geografía de esta zona en la Antigüedad, una de las especialidades de este investigador. Las numerosas láminas con los materiales e inscripciones, a las que Rada dedicó una buena parte de sus comentarios, permitieron a los especialistas sospechar de muchas de las piezas como parte de un conjunto inexplicablemente heterogéneo. En el contexto académico de la época, en el que se respetaba exageradamente el principio de autoridad, no hubo nadie con el suficiente prestigio y conocimientos como para refutar las propuestas de Rada. Sin embargo empezó a existir un estado de opinión desfavorable que no llegó a aflorar públicamente, «... justo es decir que antes de que se dijera en el extranjero y en letras de molde que entre los objetos de Yecla había falsificaciones, se venía diciendo aquí, lo decíamos en nuestras conversaciones y era, por decirlo así, cosa corriente entre los arqueólogos y aficionados» (Mélida, 1903a, 87).

Las dudas debieron aumentar significativamente, puesto que el propio Rada, en una carta a F. Fita fechada el 17 de septiembre del mismo año, comenta sobre las esculturas, «cada vez sigo creyendo más son maniquíes» (RAH 9/7585, Abascal, 1999, 22). Lo cierto es que había enviado una copia de su discurso a algunas autoridades muy representativas en la época, como Lepsius, Mommsen, Hübner y Longpérier (Mélida, 1903d, 484). Este último le contestó de forma muy «diplomática», sin dejar de señalar que ciertas inscripciones eran tan extraordinarias que provocaban verdadero asombro (Campillo, 1875, 285-286).

Sin embargo, fue E. Hübner, epigrafista de enorme prestigio, el que manifestó a las claras su convicción de que las evidencias epigráficas eran falsas y con ellas, el conjunto de los materiales procedentes del Cerro de los Santos. El disgusto de Fernández Guerra al conocer esta opinión se deja ver a las claras en su correspondencia con el erudito alemán en octubre de 1875 , indicando razonablemente que hubiera sido muy difícil falsificar tantas esculturas como habían sido directamente recogidas en el yacimiento (Miranda Valdés et alii, 2011, 171-172). Las opiniones de Hübner y Longpérier tuvieron un gran peso y la desconfianza se difundió en el ámbito internacional. La nueva salida de los vaciados a la Exposición Universal de Paris en 
1878, esta vez acompañados por algunas piezas auténticas, fue recibida con «una conspiración de silencio» (Linas, 1887, 312).

Esta grave, pero comprensible crisis, provocó nuevos estudios a fondo de la colección por parte de Heuzey (1891), Hübner (1893) y finalmente la obra fundamental de Mélida (1903-1905), consiguiendo separar en gran medida lo falso de lo auténtico. Se generaba así, en el inicio del siglo XX, un punto de inflexión en el estudio de tan singular yacimiento. Los nuevos y espectaculares hallazgos de escultura ibérica que se sucedieron en esos años, los problemas surgidos con la colección y el aspecto desolado del lugar provocaron, en expresivas palabras de Fernández de Avilés (1966, 6), el «desahucio» del Cerro, al que se colgó la etiqueta de «agotado». Hubo que esperar hasta 1962 cuando, rompiendo con estos clichés, se plantearon nuevas campañas de excavación dirigidas por A. Fernández de Avilés (1966), cuyos interesantes resultados abrieron una nueva y fructífera etapa en el conocimiento de este lugar clave de la cultura ibérica e iberorromana.

\section{AGRADECIMIENTOS}

Agradecemos a la Dra. A. Rodero su colaboración en el estudio de la colección del Museo Arqueológico Nacional. Las Dras. M. I. Martínez Navarrete (Instituto de Historia. CSIC) y L. Avilova (Instituto de Arqueología de la Academia de Ciencias de Rusia) nos han facilitado el acceso a la información original de los autores rusos sobre las Kamennye Baby. Los Drs. R. Olmos, M. Belén y L.A. Sánchez nos han ayudado también en la preparación y corrección de este trabajo. El Museo Nacional de Escultura nos ha proporcionado amablemente el catálogo de los vaciados del Cerro de los Santos correspondiente al Museo de Reproducciones Artísticas, gestión que agradecemos a la Dra. M. Bolaños y A. Campano, directora y conservador respectivamente de este centro. Los revisores anónimos han realizado comentarios relevantes que hemos intentado incorporar al trabajo. Finalmente, T. Chapa dedica un recuerdo muy especial a J. Fernández-Tresguerres, quien le proporcionó un ejemplar de la Memoria de Rada y Delgado cuando la biblioteca a la que pertenecía iba a ser desmantelada.

\footnotetext{
Profa: Dra. Teresa Chapa Brunet

Departamento de Prehistoria

Facultad de Geografía e Historia

Universidad Complutense

28040 Madrid

tchapa@ghis.ucm.es

Dr. Julio González Alcalde

Museo Nacional de Antropología

Alfonso XII, 68

28014 Madrid

jga@mncn.csic.es
}

\section{BIBLIOGRAFÍA}

ABASCAL PALAZÓN, J. M., 1999: Fidel Fita. Su legado documental en la Real Academia de la Historia, Madrid.

AGUADO, J. de D., 1875: «El Cerro de los Santos. Una aclaración», Revista Histórica, T. II, $\mathrm{n}^{\circ}$ 1, 1-3.

AMADOR DE LOS RÍOS, J., 1863: «Algunas consideraciones sobre la estatuaria durante la monarquía visigoda (II)», El Arte en España, II, 5-18.

AYARZAGÜENA SANZ, M., 1993: «La Arqueología Prehistórica y Protohistórica española en el siglo XIX», Espacio, Tiempo y Forma, Serie I. Prehistoria y Arqueología 6, 393-412.

BAYE, J. de, 2010 [1890]: De l'influence de l'art des Goths en Occident, Communication faite au Congrès Historique et Archéologique de Liège, Août 1890 (1891), Whitefish.

BIOSCA, J., 1873: «Consideraciones sobre dos medallones hallados en el Cerro de los Santos. Yecla», Memorial Numismático Español, III, 208-215.

CAMPILLO, T. del, 1875: «Bibliografía (reseña del discurso de J. de D. Rada y Delgado, «Antigüedades del Cerro de los Santos en término de Montealegre» y contestación de A. Fernández Guerra», Revista de Archivos, Bibliotecas y Museos, Año V, 5 de septiembre, no 17, 283-286.

CATÁLOGO, 1912: Catálogo del Museo de Reproducciones Artísticas. Primera parte. Escultura antigua, Imp. Hijos de Tello, Madrid.

COMMISSARIAT D'ESPAGNE, 1873: Exposition Universelle à Vienne 1873, Catalogue général de la section espagnole, Ed. du Commissariat d'Espagne, Viena.

DOMENECH, J. M., 1872: «Monumentos prehistóricos de Yecla», La Esperanza. Periódico Católico, 29 de noviembre; 2 y 11 de diciembre.

ENGEL, A., 1892: «Rapport sur une mission archéologique en Espagne (1891)», Nouvelles Archives des Missions Scientifiques et Litteraires, III, 111-219.

FERNÁNDEZ DE AVILÉS, A., 1949: «Las primeras investigaciones en el Cerro de los Santos (1860-1870) (Cuestiones de puntualización)», Boletín del Seminario de Estudios de Arte y Arqueología, XV, 57-70.

FERNÁNDEZ DE AVILÉS, A., 1966: Cerro de los Santos. Montealegre del Castillo (Albacete). Primera Campa$\tilde{n} a, 1962$, Excavaciones Arqueológicas en España 55, Madrid.

FRANCO MATA, A., 1993: «Comisiones científicas en España de 1868 a $1875 »$, en A. MARCOS POUS (Coord.), De Gabinete a Museo. Tres siglos de historia, 300-309, Madrid.

GARCÍA GUTIÉRREZ, A., 1876: «Noticia histórico-descriptiva del Museo Arqueológico Nacional», Imp. de Fortanet, Madrid.

GIMÉNEZ RUBIO, J., 1865: Memoria de apuntes para la Historia de Yecla, Imp. Juan Azorín, Yecla.

GOODRUM, M. R., 2009: «The Creation of Societies for the Study of Prehistory and Their Role in the Formation of Prehistoric Archaeology as a Discipline, 18671929», Bulletin of the History of Archaeology, 19 (2), 27-35. 
GONZÁLEZ REYERO, S., 2006: La fotografía en la arqueología española, Real Academia de la Historia, Universidad Autónoma de Madrid, Madrid.

HENSZLMANN, M., 1877: «L'Âge du Fer, étude sur l'art gothique», Congrès International d'Anthropologie et d'Archéologie Préhistoriques. Compte-Rendu de la Huitième Session a Budapest (1876), Vol I, Imprimerie Franklin-Társulat, 501-541, Budapest.

HEUZEY, L., 1891: «Statues espagnols de style gréco-phénicien», Bulletin de Correspondence Hellenique, XV, 608-625.

HÜBNER, E., 1893: Monumenta Linguae Ibericae, Reimer, Berlin.

KUBAREV, G.V., 2007: «Ancient Turkic Statues. Epic Hero or Warrior Ancestor?», Archaeology, Ethnology and Anthropology of Eurasia, 29 (1), 136-144.

LASALDE, C., 1871a: «El Cerro de los Santos. Contestación al artículo de don A.R.E.», El Liceo, 20-VIII, Albacete.

LASALDE, C., 1871b: «Primeros pobladores de España», La Ilustración de Madrid, 15 de Marzo y 30 de Marzo, Madrid.

LASALDE, C., 1879: «Estudios sobre el pueblo bastitano», Semanario Murciano, Año II, no 85, 87 a 90, 94, 95 y 98.

LINAS, Ch. de, 1877-1877: Les origines de l'orfèvrerie cloisonnée, recherches sur les divers genres d'incrustation, la joaillerie et l'art des métaux précieux, 3 vols, E. Didron, Paris.

LÓPEZ AZORÍN, F., 1994: Yecla y el Padre Lasalde, Murcia.

LÓPEZ AZORÍN, F., 2011: «El relojero de Yecla y las falsificaciones del Cerro de los Santos», en J. BLÁNQUEZ PÉREZ (Ed.), ¿Hombres o dioses? Una nueva mirada a la escultura del mundo ibérico, 279-296, Madrid.

LÓPEZ AZORÍN, F. y RUIZ MOLINA L., 2007: Memoria sobre las notables excavaciones hechas en el Cerro de los Santos. Publicadas por los Padres Escolapios (Edición comentada), Yecla.

LOSA SERRANO, F. J., 1998: El Señorio de Montealegre, Tesis Doctorales, Universidad de Castilla la Mancha, Cuenca.

LUCAS PELLICER, R., 1994: «Historiografía de la escultura ibérica hasta la Ley de 1911 ( $1^{\text {a }}$ parte)», Revista de Estudios Ibéricos, 1, 15-42.

MAIER, J., 1999: Catálogo de la Comisión de Antigüedades de la Real Academia de la Historia. Castilla-La Mancha. Catálogo e Índices, Madrid.

MARCOS POUS, A., 1993: «Origen y desarrollo del Museo Arqueológico Nacional», De Gabinete a Museo. Tres Siglos de Historia, 21-100, Madrid.

MÉLIDA, J. R., 1903a: «Las esculturas del Cerro de los Santos. Cuestión de autenticidad», Revista de Archivos, Bibliotecas y Museos, VII (2), 85-90.

MÉLIDA, J. R., 1903b: «Las esculturas del Cerro de los Santos. Cuestión de autenticidad», Revista de Archivos, Bibliotecas y Museos, VII (6), 470-485.

MÉLIDA, J. R., 1903c: «Las esculturas del Cerro de los Santos. Cuestión de autenticidad», Revista de Archivos, Bibliotecas y Museos, VII (8-9), 140-148.
MÉLIDA, J. R., 1903d, «Las esculturas del Cerro de los Santos. Cuestión de autenticidad», Revista de Archivos, Bibliotecas y Museos, VII (8-9), 247-255.

MÉLIDA, J. R., 1903e, «Las esculturas del Cerro de los Santos. Cuestión de autenticidad», Revista de Archivos, Bibliotecas y Museos, VII (11), 365-372.

MÉLIDA, J. R., 1904a, «Las esculturas del Cerro de los Santos. Cuestión de autenticidad», Revista de Archivos, Bibliotecas y Museos, VIII (X), 43-50.

MÉLIDA, J. R., 1904b, «Las esculturas del Cerro de los Santos. Cuestión de autenticidad», Revista de Archivos, Bibliotecas y Museos, VIII (8/9), 144-158.

MÉLIDA, J. R., 1904c: «Las esculturas del Cerro de los Santos. Cuestión de autenticidad», Revista de Archivos, Bibliotecas y Museos, VIII (10), 276-287.

MÉLIDA, J. R., 1905a, «Las esculturas del Cerro de los Santos. Cuestión de autenticidad», Revista de Archivos, Bibliotecas y Museos, IX (XII), 37-42.

MÉLIDA, J. R., 1905b: «Las esculturas del Cerro de los Santos. Cuestión de autenticidad», Revista de Archivos, Bibliotecas y Museos, IX (no 2), 19-38.

MEMORIA, 1871: Memoria sobre las notables excavaciones hechas en el Cerro de los Santos publicada por los Padres Escolapios de Yecla, Madrid. [Lasalde, C., Gómez, M. y Sáez del Caño, T.].

MIRANDA VALDÉS, J., GIMENO PASCUAL, H. y SÁNCHEZ MEDINA, E., 2011: Emil Hübner, Aureliano Fernández-Guerra y la epigrafia de Hispania, Correspondencia 1860-1894, Col. Antiquaria Hispanica 22, Madrid.

MUNCH, M. 1878. «Ueber die Steinfiguren (Kamene babe) auf den Tumuli des südlichen Russland», Mitteilungen der Anthropologischen Gesellschaft in Wien, Band VII, 193-214.

NAVARRO REVERTER, J., 1875: Del Turia al Danubio. Memorias de la Exposición Universal de Viena, Imprenta de José Domenech, Valencia.

PARIS, P., 1903: Essai sur l'Art et l'Industrie de l'Espagne Primitive, T.I., Imp. P.Leroux, Paris.

PLETNEVA S.A., 1974: Esculturas de piedra de los Polovets. [Polovetskie kamennye izvaianiia], Moscú.

RADA Y DELGADO, J. de D., 1875: Antigüedades del Cerro de los Santos en término de Montealegre. Discursos leídos ante la Academia de la Historia en la recepción pública del señor Juan de Dios de la Rada y Delgado. Contestación de D. Aureliano Fernández-Guerra y Orbe, Imp. T. Fortanet, Madrid.

RENTERO VILLOTA, A., 1871a: «El Cerro de los Santos. Monumento arqueológico», El Liceo, n ${ }^{\circ}$ 12-13 (23 y 30 de julio), Albacete.

RENTERO VILLOTA, A., 1871b: «El Cerro de los Santos. Cuatro palabras en contestación al Sr. Laxalde», El Liceo, $\mathrm{n}^{\circ} 17$ (27 de agosto), Albacete.

REULEAUX, F., 1891: Los Grandes Inventos en todas las esferas de la actividad humana y sus principales aplicaciones cientificas, artísticas, industriales, comerciales y domésticas, Gras y Compañía Editores, Madrid.

RUANO, E., 1987: La escultura humana de piedra en el mundo ibérico, 3 vols, Madrid. 
RUIZ BREMON, M., 1989: Los exvotos del santuario ibérico de El Cerro de los Santos, Albacete.

RUIZ MOLINA, L., 2005: «Azorín, Lasalde y la Arqueología, el Cerro de los Santos y la misteriosa Elo», Verdolay, 9, 195-214.

SÁEZ, T., 1870: (sin título, bajo el epígrafe, «Remitido»), La Esperanza. Periódico Monárquico, 25 de noviembre.

SÁEZ DEL CAÑO, T., 1871: «Las antigüedades del Cerro de los Santos», Revista de Archivos, Bibliotecas y Museos, I, 317-319.

SÁNCHEZ GÓMEZ, M. L., 2002: El santuario de El Cerro de los Santos (Montealegre del Castillo, Albacete). Nuevas aportaciones arqueológicas, Albacete.
SANPERE I MIQUEL, M., 1880a: «Contribución al estudio de la religión de los Iberos», Revista de Ciencias Históricas I (Abril), 1-44.

SANPERE I MIQUEL, M., 1880b: "Los “origens $i$ Fonts de la Nació Catalana" en el extranjero», Revista de Ciencias Históricas, I (Mayo), 162-176.

SAVIRÓN, P., 1875: «Noticia de varias excavaciones del Cerro de los Santos en término de Montealegre (Montealegre del Castillo, Albacete)», Revista de Archivos, Bibliotecas y Museos, 5, 125-129; 161-164; 193-197; 229-234 y 245-247.

Recepción: 21-05-2013

Aceptación: 11-07-2013 